\title{
New insight into the SSC8 genetic determination of fatty acid composition in pigs
}

\author{
Manuel Revilla', Yuliaxis Ramayo-Caldas ${ }^{1,2}$, Anna Castelló ${ }^{1,2}$, Jordi Corominas ${ }^{1,2}$, Anna Puig-Oliveras ${ }^{1,2}$, \\ Noelia Ibáñez-Escriche ${ }^{3}$, María Muñoz ${ }^{4}$, Maria Ballester ${ }^{1,2}$ and Josep M Folch ${ }^{1,2^{*}}$
}

\begin{abstract}
Background: Fat content and fatty acid composition in swine are becoming increasingly studied because of their effect on sensory and nutritional quality of meat. A QTL (quantitative trait locus) for fatty acid composition in backfat was previously detected on porcine chromosome 8 (SSC8) in an Iberian $\times$ Landrace $F_{2}$ intercross. More recently, a genome-wide association study detected the same genomic region for muscle fatty acid composition in an Iberian $x$ Landrace backcross population. ELOVL6, a strong positional candidate gene for this QTL, contains a polymorphism in its promoter region (ELOVL6:C.-533C $<$ T), which is associated with percentage of palmitic and palmitoleic acids in muscle and adipose tissues. Here, a combination of single-marker association and the haplotype-based approach was used to analyze backfat fatty acid composition in 470 animals of an Iberian $x$ Landrace $F_{2}$ intercross genotyped with 144 SNPs (single nucleotide polymorphisms) distributed along SSC8.

Results: Two trait-associated SNP regions were identified at $93 \mathrm{Mb}$ and $119 \mathrm{Mb}$ on SSC8. The strongest statistical signals of both regions were observed for palmitoleic acid (C16:1(n-7)) content and C18:0/C16:0 and C18:1(n-7)/C16:1 $(\mathrm{n}-7)$ elongation ratios. MAML3 and SETD7 are positional candidate genes in the $93 \mathrm{Mb}$ region and two novel microsatellites in MAML3 and nine SNPs in SETD7 were identified. No significant association for the MAML3 microsatellite genotypes was detected. The SETD7:C.700G > T SNP, although statistically significant, was not the strongest signal in this region. In addition, the expression of MAML3 and SETD7 in liver and adipose tissue varied among animals, but no association was detected with the polymorphisms in these genes. In the $119 \mathrm{Mb}$ region, the ELOVL6:C.-533C > T polymorphism showed a strong association with percentage of palmitic and palmitoleic fatty acids and elongation ratios in backfat.

Conclusions: Our results suggest that the polymorphisms studied in MAML3 and SETD7 are not the causal mutations for the QTL in the $93 \mathrm{Mb}$ region. However, the results for ELOVL6 support the hypothesis that the ELOVL6:C.-533C > T polymorphism has a pleiotropic effect on backfat and intramuscular fatty acid composition and that it has a role in the determination of the QTL in the $119 \mathrm{Mb}$ region.
\end{abstract}

\section{Background}

One of the main sources of human-consumed meat is pork, which represents more than $40 \%$ of the meat produced worldwide [1]. The success of pig production is strongly related to improvements in growth and carcass yield. Meat-quality traits are essential for the processing industry and end-consumer acceptance [2], and, as a result, these qualitative traits have been the subject of many

\footnotetext{
* Correspondence: josepmaria.folch@uab.es

${ }^{1}$ Centre de Recerca en Agrigenòmica (CRAG), Consorci CSIC-IRTA-UAB-UB,

Campus UAB, Bellaterra 08193, Spain

Departament de Ciència Animal i dels Aliments, Facultat de Veterinària,

Universitat Autònoma de Barcelona, Bellaterra 08193, Spain

Full list of author information is available at the end of the article
}

studies in breeding programs. Fat content and fatty acid (FA) composition in swine are becoming increasingly studied because of their effect on sensory and nutritional quality of meat. They determine important sensory and technological aspects of pork and meat products because of their influence on the melting point and oxidative status of porcine tissues [3]. In addition, the amount and type of fat in the diet have a major impact on human health. The high consumption of saturated fatty acids (SFA) raises plasma LDL-cholesterol, which is a major risk factor for arteriosclerosis and coronary heart disease (CHD) [4-6]. However, recent studies suggest that individual SFA have different physiological effects. Indeed, lauric acid (12:0),

\section{Biomed Central}

(c) 2014 Revilla et al.; licensee BioMed Central Ltd. This is an Open Access article distributed under the terms of the Creative Commons Attribution License (http://creativecommons.org/licenses/by/2.0), which permits unrestricted use, distribution, and reproduction in any medium, provided the original work is properly credited. The Creative Commons Public Domain Dedication waiver (http://creativecommons.org/publicdomain/zero/1.0/) applies to the data made available in this article, unless otherwise stated. 
myristic acid (14:0) and palmitic acid (16:0) raise LDL and HDL cholesterol plasma levels, whereas stearic acid (C18:0) is considered neutral $[7,8]$, although some epidemiologic evidence suggests that stearic acid (C18:0) is associated with $\mathrm{CHD}$ [9]. In contrast, cis-monounsaturated fatty acids (MUFA) and polyunsaturated fatty acids (PUFA) are beneficial for human health. PUFA have been shown to protect against CHD [10], whereas MUFA are also considered to have a hypocholesterolemic effect [11] and, in addition, to have a beneficial effect on insulin sensitivity [12].

A few QTL (quantitative trait loci) for FA composition have been reported on porcine chromosome 8 (SSC8) in $\mathrm{F}_{2}$ Duroc x Large White [13], $\mathrm{F}_{2}$ White Duroc x Erhualian [14] and Duroc [15] populations. Using an Iberian $x$ Landrace $F_{2}$ intercross (IBMAP) [16], a QTL was identified on SSC8 for percentages of palmitic (16:0) and palmitoleic (C16:1(n-7)) FA and for average length of FA in backfat (BF). Recently, a genome-wide association study (GWAS) conducted in a backcross population (BC1_LD; 25\% Iberian and $75 \%$ Landrace) led to the identification of five genomic regions on SSC8 associated with intramuscular fat in longissimus dorsi (IMF) FA composition [17]. In addition, a study that combined a linkage QTL scan and a GWAS on the same backcross revealed significant pleiotropic regions with effects on palmitic (C16:0) and palmitoleic (C16:1(n-7)) FA in both IMF and BF tissues [18].

The main goals of this work were: (1) to study the QTL architecture for FA composition on SSC8 in the $F_{2}$ generation of the IBMAP cross using a panel of 144 informative SNPs, and (2) to analyze additional positional candidate genes.

\section{Methods}

\section{Animal samples}

Animals used in this study belong to the IBMAP experimental population [19]. Two Iberian (Guadyerbas line) boars were crossed with 30 Landrace sows to generate the $F_{1}$ generation. Six $F_{1}$ boars were coupled with $67 F_{1}$ sows to obtain $470 \mathrm{~F}_{2}$ animals. In addition, gene-expression analyses were carried out on 56 females from a backcross (BC1_LD) generated by crossing five $\mathrm{F}_{1}$ (Iberian $\mathrm{x}$ Landrace) boars with 23 Landrace sows. All animals were maintained under intensive conditions and feeding was ad libitum with a cereal-based commercial diet. The experiments were performed in Europe following national and institutional guidelines for the ethical use and treatment of animals in experiments. In addition, the protocol was approved by the Ethical Committee of the Institution (IRTA Institut de Recerca i Tecnologia Agroalimentàries). $\mathrm{F}_{2}$ animals were slaughtered at an average age of $175.5 \pm$ 0.3 days. However, tissues for RNA extraction were not isolated from animals of the $\mathrm{F}_{2}$ generation. Backcross animals were slaughtered at an average age of $179.8 \pm$
2.6 days, and samples of liver and adipose tissue were collected, snap-frozen in liquid nitrogen and stored at $-80^{\circ} \mathrm{C}$ until analysis.

Genomic DNA was extracted from blood samples of all animals by the phenol-chloroform method, as described elsewhere.

\section{Traits analyzed}

The composition of 10 FA in IMF and BF (taken between the third and the fourth ribs) tissues was determined by gas chromatography as described in $[16,17,19]$. Subsequently, the percentage of each FA, relative to the total FA, was calculated as well as the global percentages of SFA, MUFA, PUFA and related indices, including desaturation and elongation indices.

\section{Genotyping and quality control}

A total of 470 animals were genotyped for 144 SNPs located on SSC8; these include a selection of 142 informative SNPs derived from the Porcine SNP60K BeadChip [20] and two SNPs that corresponded to the previously detected polymorphisms in the FABP2 [21] and MTTP [22] genes. These SNPs [See Additional file 1: Table S1] were included in a custom-generated panel, genotyped using a Veracode Golden Gate Genotyping Kit (Illumina Inc.) and analyzed with a Bead Xpress Reader (Illumina Inc.). SNP positions were based on the whole-genome sequence assembly 10.2 build of Sus scrofa (http://www. animalgenome.org/repository/pig/). All genotypes were assigned using the GenomeStudio software (Illumina Inc.). Markers that had a minor allele frequency (MAF) lower than $5 \%$ and missing genotypes that had a frequency greater than 5\% were removed using PLINK [23] software. In total, 133 SNPs (92\%) passed this quality-threshold filter and were used in the subsequent analysis. Genotypes of all the parents were obtained with the $60 \mathrm{~K} \mathrm{SNP} \mathrm{chip}$ (Illumina) [17] or by pyrosequencing [21,22].

SNPs SETD7:C.-1034T> G, SETD7:c.700G > T and ELOVL 6:c. $-533 C>T$ were genotyped using the KASP SNP genotyping system platform (http://www.lgcgenomics.com/ genotyping/). Besides these, two new microsatellites in the $M A M L 3$ gene were genotyped by PCR amplification and capillary electrophoresis and fluorescent detection using an ABI Prism 3730 DNA Analyzer (Applied Biosystems).

Fifty-six animals of the BC1_LD were genotyped for SNPs SETD7:C. $-1034 T>G$ and SETD7:C.700G $>T$ and the two $M A M L 3$ microsatellites for gene-expression studies. In addition, a subset of $168 \mathrm{~F}_{2}$ animals were genotyped for SNPs ELOVL6:C.-533C > T, SETD7:c.700G > T and the two $M A M L 3$ microsatellites for association studies. All parents and grandparents of these animals were also genotyped in the same way. 


\section{Association analysis}

Association analysis was performed for FA composition and indices of FA metabolism in $470 \mathrm{~F}_{2}$ animals. A mixed model that accounts for additive effects was performed using Qxpak 5.0 [24]:

$$
y_{i j l k m}=\operatorname{Sex}_{i}+\text { Batch }_{j}+\beta c_{l}+\lambda_{l} a_{k}+u_{l}+e_{i j l k m},
$$

where $y_{\mathrm{ijlkm}}$ is the $\mathrm{l}^{\text {th }}$ individual record, sex (two levels) and batch (five levels) are fixed effects, $\beta$ is a covariate coefficient with $\mathrm{c}$ being carcass weight, $\lambda_{\mathrm{l}}$ is a $-1,0,+1$ indicator variable depending on the $1^{\text {th }}$ individual genotype for the $\mathrm{k}^{\text {th }} \mathrm{SNP}, \mathrm{a}_{\mathrm{k}}$ represents the additive effect associated with SNP, $\mathrm{u}_{1}$ represents the infinitesimal genetic effect treated as random and distributed as $\mathrm{N}\left(0, \mathbf{A} \sigma_{\mathrm{u}}\right)$ where $\mathbf{A}$ is a numerator of the kinship matrix and $e_{i j l k m}$ is the residual. A similar model that fitted different QTL effects was used to test the hypothesis of the presence of two QTL located in the studied regions with effects $a_{1}$ and $\mathrm{a}_{2}$ on the same FA:

$$
\begin{aligned}
y_{\mathrm{ijlkm}}= & \operatorname{Sex}_{\mathrm{i}}+\text { Batch }_{\mathrm{j}}+\beta \mathrm{c}_{\mathrm{l}}+\lambda_{\mathrm{l}} \mathrm{a}_{1 \mathrm{k}}+\lambda_{\mathrm{l}} \mathrm{a}_{2 \mathrm{k}}+\mathrm{u}_{\mathrm{l}} \\
& +\mathrm{e}_{\mathrm{ijlkm}},
\end{aligned}
$$

The $R$ package q-value [25] was used to calculate the false-discovery rate (FDR), and the cut-off of the significant association at the whole-genome level was set at the q-value $\leq 0.05$. Version 2.15.2 of $\mathrm{R}$ [26] was used to calculate the descriptive statistics for the 10 analyzed traits and their related indices.

For linkage and linkage disequilibrium (LDLA) analysis, haplotypes were reconstructed using DualPHASE software [27], which exploits population (linkage disequilibrium) and family information (Mendelian segregation and linkage) in a Hidden Markov Model setting. Then, QTL fine-mapping was performed for the most significant traits C16:1(n-7), C18:0/C16:0, C16:1(n-7)/ C18:1(n-7), and the FA average chain-length (ACL) by applying the mixed model:

$$
\mathbf{y}=\mathbf{X b}+\mathbf{Z}_{\mathbf{h}} \mathbf{h}+\mathbf{Z}_{\mathbf{u}} \mathbf{u}+\mathbf{e}
$$

in which $\mathbf{b}$ is a vector of fixed effects (sex and batch), $\mathbf{h}$ is the vector of random QTL effects corresponding to the $\mathrm{K}$ cluster defined by the Hidden State, $\mathbf{u}$ is the vector of random individual polygenic effects and $\mathbf{e}$ is the vector of individual error.

\section{Amplification and sequencing of the pig MAML3 and SETD7 genes}

Genomic DNA samples from 10 individuals of the BC1_LD and two Iberian boars were used to amplify and sequence the proximal promoter and exon 1 of the $M A M L 3$ and SETD7 genes.

A 931-bp region of the MAML3 gene was amplified and sequenced in two overlapping fragments of $517 \mathrm{bp}$ and 663 bp. Primers [See Additional file 2: Table S2] were designed based on a SSC8 sequence of a Sus scrofa mixed breed [ENSSSCG00000009060] available from the Sscrofa10.2 database and conserved with the human $M A M L 3$ gene [ENSG00000196782].

For the SETD7 gene, two overlapping fragments of 473 bp and 478 bp were amplified and sequenced. Primers [See Additional file 2: Table S2] were designed based on a SSC8 sequence of a Sus scrofa mixed breed [ENSSSCG00000030396] available from the Sscrofa10.2 database and conserved with the human SETD7 gene [ENSG00000145391].

All primers were designed using the PRIMER3 software [28] and were validated using the PrimerExpress 2.0 software (Applied Biosystems).

PCR (polymerase chain reactions) were carried out in a total volume of $25 \mu \mathrm{L}$ containing 0.6 units of AmpliTaq Gold (Applied Biosystems), 1.5 to $2.5 \mathrm{mM} \mathrm{MgCl}_{2}$ depending on the primers [See Additional file 2: Table S2], $0.2 \mathrm{mM}$ of each dNTP, $0.5 \mu \mathrm{M}$ of each primer and $20 \mathrm{ng}$ of genomic DNA. The temperature profile was $94^{\circ} \mathrm{C}$ for $10 \mathrm{~min}$ and 35 cycles at $94^{\circ} \mathrm{C}$ for $1 \mathrm{~min}, 58^{\circ} \mathrm{C}$ to $62^{\circ} \mathrm{C}$ depending on the primers [See Additional file 2: Table S2] for $1 \mathrm{~min}$ and $72^{\circ} \mathrm{C}$ for $1.5 \mathrm{~min}$, including a final step of $7 \mathrm{~min}$ at $72^{\circ} \mathrm{C}$. Gradient parameters were determined based on size and GC content of the amplicon. The samples were then analyzed on $1.5 \%$ agarose gels. Purification was performed using an Exonuclease I and FastAP ${ }^{\mathrm{ra}}$ Thermosensitive Alkaline Phosphatase [29]. For the sequencing reaction, we used the Big Dye Terminator v.3.1 Cycle Sequencing Kit and an ABI Prism 3730 DNA analyzer was employed (Applied Biosystems). Polymorphisms were checked through the Seq scape v2.1.1 program (Applied Biosystems).

\section{Detection of microsatellite polymorphisms}

Based on the sequencing results of the promoter region and exon 1 of the $M A M L 3$ gene, two new microsatellites were identified. Both microsatellites were independently amplified using fluorescent primers [See Additional file 2: Table S2]. PCR were performed in a $25-\mu \mathrm{L}$ reaction mix containing $20 \mathrm{ng}$ of genomic DNA, $0.2 \mathrm{mM}$ of each dNTP, $2.5 \mathrm{mM} \mathrm{MgCl} 2,0.5 \mu \mathrm{M}$ of each PCR primer and 0.6 units of AmpliTaq Gold (Applied Biosystems). PCR were run as follows: $94^{\circ} \mathrm{C}$ for $10 \mathrm{~min}, 35$ cycles of $94^{\circ} \mathrm{C}$ for $1 \mathrm{~min}, 58^{\circ} \mathrm{C}$ for $1 \mathrm{~min}, 72^{\circ} \mathrm{C}$ for $1.5 \mathrm{~min}$ and a final extension step at $72^{\circ} \mathrm{C}$ for $7 \mathrm{~min}$. The two amplicons were mixed at a ratio of 1:3 (HEX:FAM) and analyzed using capillary electrophoresis on an ABI Prism 3730 DNA analyzer (Applied Biosystems) and the ROX-500 GeneScan Size Standard. The peak height of each product was determined using Peak Scanner 2 software (Applied Biosystems). 


\section{RNA isolation and CDNA synthesis}

Total RNA was extracted from liver and BF tissues using the RiboPure kit (Ambion), according to the manufacturer's recommendations. RNA was then quantified using a NanoDrop ND-1000 spectrophotometer (NanoDrop products) and RNA integrity was assessed with an Agilent Bioanalyzer-2100 (Agilent Technologies). One $\mu \mathrm{g}$ of total RNA of each sample was reverse-transcribed using the High-Capacity cDNA Reverse Transcription kit (Applied Biosystems) in a reaction volume of $20 \mu \mathrm{L}$.

\section{Gene-expression quantification}

Fifty-six females of the BC1_LD were used to quantify gene expression. The expression of MAML3 and SETD7 was analyzed using the 48.48 microfluidic dynamic array IFC chip (Fluidigm) according to the manufacturer's instructions. Briefly, $2 \mu \mathrm{L}$ of 1:5 diluted cDNA was preamplified using 2X Taqman PreAmp Master Mix (Applied Biosystems) and $50 \mathrm{nM}$ of each primer pair in $5-\mu \mathrm{L}$ reaction volume. The cycling program consisted of an initial step of $10 \mathrm{~min}$ at $95^{\circ} \mathrm{C}$ followed by 16 cycles of $15 \mathrm{~s}$ at $95^{\circ} \mathrm{C}$ and $4 \mathrm{~min}$ at $60^{\circ} \mathrm{C}$. At the end of this pre-amplification step, the reaction products were diluted 1:5 (diluted preamplification samples). RT-qPCR on the dynamic array chips was conducted on the BioMarkTM system (Fluidigm). A $5-\mu \mathrm{L}$ pre-mix sample containing $2.5 \mu \mathrm{L}$ of SsoFast EvaGreen Supermix with Low ROX (Bio-Rad), $0.25 \mu \mathrm{L}$ of DNA Binding Dye Sample Loading Reagent (Fluidigm) and $2.25 \mu \mathrm{L}$ of diluted pre-amplification samples (1:16 or 1:64 from the diluted pre-amplification samples from liver and BF samples, respectively), as well as a $5-\mu \mathrm{L}$ assay mix containing $2.5 \mu \mathrm{L}$ of Assay Loading Reagent (Fluidigm), $2.25 \mu \mathrm{L}$ of DNA Suspension Buffer (Teknova) and $0.25 \mu \mathrm{L}$ of $100 \mu \mathrm{M}$ primer pairs (500 nM in the final reaction) were mixed inside the chip using the IFC controller MX (Fluidigm). The cycling program consisted of an initial step of $60 \mathrm{~s}$ at $95^{\circ} \mathrm{C}$ followed by 30 cycles of $5 \mathrm{~s}$ at $96^{\circ} \mathrm{C}$ and $20 \mathrm{~s}$ at $60^{\circ} \mathrm{C}$. A dissociation curve was also drawn for each primer pair.

Data were collected using the Fluidigm Real-Time PCR analysis software 3.0.2 (Fluidigm) and analyzed with the DAG expression software 1.0.4.11 [30] using standard curves for relative quantification. Relative standardcurves with a four-fold dilutions series $(1 / 4,1 / 16,1 / 64$, $1 / 256,1 / 1024)$ of a pool of 10 cDNA samples were constructed for each gene to extrapolate the value of the quantities of each studied sample. Of the four endogenous genes tested ( $A C T B, B 2 M, H P R T 1, T B P), A C T B$ and TBP had the most stable expression [31] in both tissues. The normalized quantity values of each sample and assay were used to compare our data.

PCR primer sequences [See Additional file 2: Table S2] were designed using PrimerExpress 2.0 software (Applied Biosystems).
Mean values between genotypes were compared using a linear model implemented in $\mathrm{R}$, which performs a single stratum analysis of variance considering sex and batch as fixed effects. Differences were considered statistically significant at a p-value of 0.05 .

\section{Results and discussion}

Association studies and combined linkage disequilibrium and linkage analyses

A custom panel of 144 SNPs located on SSC8 was used to genotype $470 \mathrm{~F}_{2}$ animals. Association analyses for the BF FA composition in the $\mathrm{C} 14: 0$ to $\mathrm{C} 22: 0$ ranges were performed with genotypes from a subset of 133 SNPs (call rate $>0.99$ ). Statistically significant associations were found (Table 1) for the SFA myristic (C14:0), palmitic (C16:0) and stearic acids (C18:0). Among MUFA, palmitoleic acid (C16:1(n-7)) and oleic acid (C18:1(n-9)) were associated, whereas for PUFA only eicosadienoic acid (C20:2(n-6)) was significant. Similarly, the ACL metabolic ratio showed a significant association. A strong association signal was found for the $\mathrm{C} 16: 1(\mathrm{n}-7) / \mathrm{C} 16: 0$ desaturation ratio and two elongation ratios: $\mathrm{C} 18: 0 / \mathrm{C} 16: 0$ and $\mathrm{C} 18: 1$ $(\mathrm{n}-7) / \mathrm{C} 16: 1(\mathrm{n}-7)$.

Two regions that contain trait-associated SNPs (TAS) were clearly visualized in the association plots at around $93 \mathrm{Mb}$ and $119 \mathrm{Mb}$ for all of the above-mentioned FA and indices with the exception of the C20:2(n-6)/C18:2 (n-6) elongation ratio, which showed only one significant TAS region at $120.99 \mathrm{Mb}$ (Table 1). For all significant traits, the $119 \mathrm{Mb}$ TAS region showed a stronger signal than the $93 \mathrm{Mb}$ region. The strongest effects of both TAS regions were found for palmitoleic acid (C16:1 (n-7)) content and C18:0/C16:0 and C18:1(n-7)/C16:1 (n-7) elongation ratios.

A combination of linkage disequilibrium and linkage analysis (LDLA) was then performed for the most significantly associated traits [See Additional file 2: Table S3]. With this haplotype-based approach, it is possible to simultaneously exploit linkage analysis and linkage disequilibrium. Several studies have shown the usefulness of this strategy for fine-mapping and QTL interval reduction $[27,32]$. The LDLA study identified the two TAS regions by association analysis, with the $119 \mathrm{Mb}$ region showing the strongest statistical signal for all analyzed traits. Figure 1 shows the two genomic regions identified for the $\mathrm{C} 18: 0 / \mathrm{C} 16: 0$ elongation ratio. Plots of the other three traits analyzed are shown in Additional file 3: Figure S1.

In order to determine whether one or two QTL were segregating on SSC8 for the BF FA and their indices, models fitting one QTL against a model considering two different QTL were tested. Results of the LR test indicated that the model with two QTL was the most likely for the 10 traits analyzed [See Additional file 2: Table S4]. 


\begin{tabular}{|c|c|c|c|c|c|}
\hline Trait & Chromosomal region (Mb) & SNP & LR & $P$-value & $a$ (SE) \\
\hline \multirow[t]{2}{*}{ C14:0 } & 93.79 & ALGA0048597 & 17.2127 & $3.34 \mathrm{E}-05$ & $0.042(0.019)$ \\
\hline & 117.55 & ALGA0049135 & 18.7843 & $1.46 \mathrm{E}-05$ & $0.055(0.016)$ \\
\hline \multirow[t]{2}{*}{ C16:0 } & 93.72 & ALGA0048594 & 32.4610 & $1.22 \mathrm{E}-08$ & $0.573(0.881)$ \\
\hline & 117.66 & ALGA0049139 & 48.1404 & $3.97 \mathrm{E}-12$ & $0.599(0.871)$ \\
\hline \multirow[t]{2}{*}{ C18:0 } & 91.56 & H3GA0025111 & 11.7215 & $6.18 \mathrm{E}-04$ & $-0.254(0.630)$ \\
\hline & $119.85^{1}$ & INRA0030422 & 20.6040 & $5.65 \mathrm{E}-06$ & $-0.366(0.616)$ \\
\hline \multirow[t]{2}{*}{ C16:1(n-7) } & 91.56 & H3GA0025111 & 42.9598 & $5.59 \mathrm{E}-11$ & $0.163(0.082)$ \\
\hline & $119.85^{1}$ & INRA0030422 & 71.7870 & $1.11 \mathrm{E}-18$ & $0.223(0.082)$ \\
\hline \multirow[t]{2}{*}{ C18:1(n-9) } & 93.66 & ALGA0048589 & 22.4009 & $2.21 \mathrm{E}-06$ & $-0.651(1.589)$ \\
\hline & 117.66 & ALGA0049139 & 33.1059 & 8.73E-09 & $-0.672(1.571)$ \\
\hline \multirow[t]{2}{*}{$C 20: 2(n-6)$} & 94.73 & MARC0097057 & 23.1170 & $1.52 \mathrm{E}-06$ & $-0.032(0.017)$ \\
\hline & 117.55 & ALGA0049135 & 23.9259 & $1.00 \mathrm{E}-06$ & $-0.039(0.017)$ \\
\hline \multirow[t]{2}{*}{ ACL } & 93.72 & ALGA0048594 & 46.5350 & $9.00 \mathrm{E}-12$ & $-0.020(0.001)$ \\
\hline & 117.66 & ALGA0049139 & 71.4236 & $1.11 \mathrm{E}-16$ & $-0.021(0.001)$ \\
\hline \multirow[t]{2}{*}{$\mathrm{C} 16: 1(n-7) / C 16: 0$} & 91.56 & H3GA0025111 & 22.7521 & $1.84 \mathrm{E}-06$ & $0.006(0.000)$ \\
\hline & $119.85^{1}$ & INRA0030422 & 37.4524 & $9.37 \mathrm{E}-10$ & $0.008(0.000)$ \\
\hline \multirow[t]{2}{*}{ C18:0/C16:0 } & 91.56 & H3GA0025111 & 47.8703 & $4.55 \mathrm{E}-12$ & $-0.023(0.002)$ \\
\hline & $119.85^{1}$ & INRA0030422 & 76.1635 & $1.11 \mathrm{E}-16$ & $-0.032(0.002)$ \\
\hline \multirow[t]{2}{*}{ C18:1(n-7)/C16:1(n-7) } & 93.72 & ALGA0048594 & 32.8062 & $1.02 \mathrm{E}-08$ & $-0.076(0.016)$ \\
\hline & $119.85^{1}$ & INRA0030422 & 61.0692 & $5.55 \mathrm{E}-15$ & $-0.089(0.015)$ \\
\hline$C 20: 2(n-6) / C 18: 2(n-6)$ & 120.99 & ALGA0049254 & 13.8456 & $1.98 \mathrm{E}-04$ & $-0.003(0.000)$ \\
\hline
\end{tabular}

$\mathrm{LR}=$ Likehood ratio test values; $a$ (SE): additive effect (standard error); ${ }^{1}$ SNPs SIRI0000509 (119.73 Mb) and H3GA0025321 (119.89 Mb) showed the same $P$-value.

Previously, a QTL scan for BF FA composition was performed with 369 animals from the same $F_{2}$ generation [16], but only six microsatellite markers were genotyped. A clear effect of SSC8 markers was observed only for percentages of palmitic (C16:0) and palmitoleic (C16:1(n-7)) FA and ACL. A suggestive effect on percentage of oleic acid (C18:1(n-9)) was also observed. However, the confidence interval for this QTL was greater than $30 \mathrm{cM}$. Two other studies of our group analyzed positional candidate genes for this QTL, i.e. FABP2 [21] and MTTP [22], but the localization of the QTL was not refined. In addition, QTL for IMF palmitic (C16:0) FA composition have been reported in a Duroc $x$ Large White $F_{2}$ cross [13] and for stearic (C18:0) FA in a White Duroc x Erhualian $F_{2}$ cross [14].

A GWAS for IMF FA composition [17] with genotypes from the $60 \mathrm{~K}$ SNP chip (Illumina) was carried out using 144 animals from a related backcross population (BC1_LD). The strongest signals on SSC8 were observed for the palmitoleic $(\mathrm{C} 16: 1(\mathrm{n}-7))$ FA content and the C18:1(n-7)/C16:1(n-7) ratio for SNPs ALGA0048684 and SIRI0000509, which in the Sscrofa10.2 assembly are located at $99.2 \mathrm{Mb}$ and $119.7 \mathrm{Mb}$, respectively. Furthermore, two significant pleiotropic regions (at $93.3 \mathrm{Mb}$ -
99.5 Mb and 110.9 Mb - 126.9 Mb) with effects on palmitoleic (C16:1(n-7)) FA in both IMF and BF tissues have been identified in the same backcross [18]. For palmitic (C16:0) FA, a large (83.8 Mb - 130.6 Mb) chromosomal interval was significant for both BF and IMF [18].

Here, two QTL at approximately $93 \mathrm{Mb}$ and $119 \mathrm{Mb}$ were detected and affected the BF composition of the six FA and the four indices mentioned above in the $470 \mathrm{~F}_{2}$ animals. The palmitoleic (C16:1(n-7)) FA QTL on SSC8 have been shown to be segregating in different crosses of the IBMAP population, and both QTL have a pleiotropic effect on BF and IMF FA deposits.

\section{Gene annotation and identification of polymorphisms in positional candidate genes}

Gene annotation of the two TAS genomic regions allowed us to identify genes related to FA metabolism. In the first region, the genes mastermind-like 3 (MAML3) (at position $92.67 \mathrm{Mb}$ ) and SET domain containing lysine methyltransferase 7 (SETD7) (at position $93.13 \mathrm{Mb}$ ) were found. Both genes have recently been reported in a predicted coassociation gene network for intramuscular FA composition in pigs (Ramayo et al., 2013; unpublished observations). 


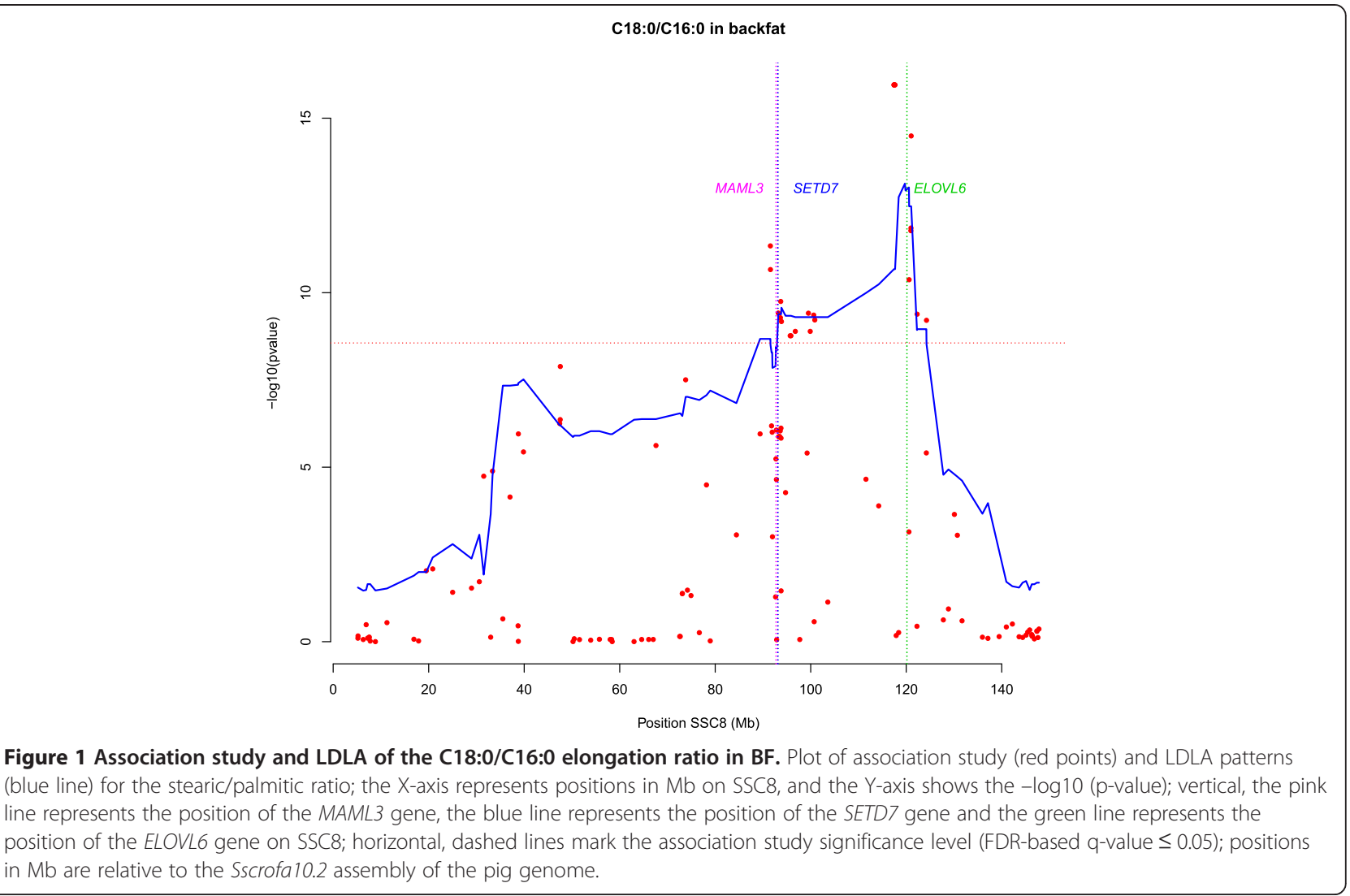

$M A M L 3$ is a member of the Mam gene family, which plays an essential role in the stabilization of Notch transcriptional activation complexes [33]. This Notch signaling pathway mediates short-range communication between cells, and it has recently been associated with the regulation of lipogenesis and gluconeogenesis in liver [34]. A 931-bp fragment of the pig MAML3 gene that covers part of the promoter region and part of exon 1, was amplified from genomic DNA and sequenced. Two novel microsatellites were found: $M A M L 3 \_M S 1$, a $(\mathrm{CA})_{\mathrm{n}}$ tandem repeat located in the promoter region and MAML3_MS2, a $(\mathrm{CGG})_{\mathrm{n}}$ tandem repeat identified in exon 1 . The variability of both microsatellites is described in Table 2.

The product of the SETD7 gene is a histone methyltransferase that specifically monomethylates Lys-4 of histone $\mathrm{H} 3$ [35] and, thus, it is involved in the epigenetic transcriptional regulation of genes, activating genes such as collagenase or insulin [36]. To identify polymorphims in the porcine SETD7 gene, a 839-bp fragment of the SETD7 promoter and exon 1 was amplified from genomic DNA and sequenced. In addition, the identification of polymorphisms in the entire coding region of the SETD7 gene was performed using RNA-Seq data [37] with the Integrative Genomics Viewer (IGV) software (http://www.broadinstitute.org/igv/). Alignment and analysis of these sequences led to the identification of nine polymorphisms (Table 3). Two of these polymorphisms were used to genotype BC1_LD animals, one located in the promoter region (SETD7:c.-1034T>G) and one nonsynonymous polymorphism in exon 6 (SETD7:c.700G > T), which determines an amino-acid change of valine to leucine. Apart from the fact that these SNPs are located in the SETD7 gene, they were selected because they showed divergent allelic frequencies between the Iberian and Landrace IBMAP founders i.e. the SETD7:C.-1034 T and SETD7:C.700 $T$ alleles were fixed in the Iberian boars. Complete linkage disequilibrium between the two SNPs was observed in the genotyped BC1_LD animals and, thus, only SETD7:c.700G > T was further genotyped in 168 animals belonging to the $\mathrm{F}_{2}$ generation.

Table 2 Microsatellites identified in the MAML3 gene

\begin{tabular}{|c|c|c|c|c|}
\hline SSR locus & Repeat & $5^{\prime}$ fluorescent label & Number of alleles & Size of alleles \\
\hline MAML3_MS1 & $(C A) n$ & HEX & 8 & $233,239,243,245,247,251,257,259$ \\
\hline MAML3_MS2 & $(C G G) n$ & FAM & 2 & 135,138 \\
\hline
\end{tabular}


Table 3 Polymorphisms identified in the proximal promoter and coding regions of the SETD7 gene

\begin{tabular}{lllll}
\hline Gene localization & Position (bp) & Ref $^{\mathbf{4}}$ & Pol $^{\mathbf{5}}$ & Aminoacid change \\
\hline Promoter $^{\mathbf{1}}$ & -1300 & $\mathrm{~A}$ & $\mathrm{G}$ & \\
& $-1034^{3}$ & $\mathrm{~T}$ & $\mathrm{G}$ & \\
& -980 & $\mathrm{C}$ & $\mathrm{A}$ & \\
& -632 & $\mathrm{~T}$ & $\mathrm{C}$ & \\
Exon $^{\mathbf{2}}$ & 462 & $\mathrm{C}$ & $\mathrm{T}$ & \\
Exon $^{\mathbf{2}}$ & $700^{3}$ & $\mathrm{G}$ & $\mathrm{T}$ & VAL/LEU \\
& 708 & $\mathrm{G}$ & $\mathrm{A}$ & \\
Exon $^{\mathbf{2}}$ & 807 & $\mathrm{C}$ & $\mathrm{T}$ & \\
Exon $^{\mathbf{2}}$ & 960 & $\mathrm{C}$ & $\mathrm{T}$ & \\
\hline
\end{tabular}

${ }^{1}$ Positions relative to the transcription start-site using, as reference, the GenBank ENSSSCG00000030396 sequence; ${ }^{2}$ referring to the coding region, using RNA-Seq data; ${ }^{3}$ SNPs genotyped; ${ }^{4}$ Ref $=$ nucleotide in the reference sequence; ${ }^{5} \mathrm{Pol}=$ polymorphisms found

In the second region, the ELOVL6 gene was identified at position $120.12 \mathrm{Mb}$. The ELOVL6 gene is a strong positional and functional candidate gene involved in de novo lipogenesis and acts on the elongation of SFA and MUFA. A polymorphism in the promoter region of this gene (ELOVL6:C.-533C > T) has previously been associated with percentages of palmitic and palmitoleic FA in muscle and backfat in the BC1_LD population [38]. In addition, expression of the ELOVL6 gene was lower in the backfat of animals with the Iberian allele in comparison to those with the Landrace allele. As expected from the elongation function of this gene, a lower ELOVL6 expression was associated with a higher percentage of palmitic and palmitoleic FA in muscle and adipose tissue [38].

Based on our results, the observed effects on FA composition and indices are concordant with a lower expression of the ELOVL6 gene in animals with the Iberian allele [38] for both TAS regions (Figure 2). ELOVL6 elongates palmitic (C16:0) to stearic (C18:0), and palmitoleic $(\mathrm{C} 16: 1(\mathrm{n}-7))$ to vaccenic $(\mathrm{C} 18: 1(\mathrm{n}-7))$ FA. Thus, a lower ELOVL6 activity associated with the Iberian allele will directly decrease these elongation ratios. Moreover, as observed, a lower ELOVL6 activity will result in the accumulation of palmitic (C16:0) and palmitoleic (C16:1 $(\mathrm{n}-7)) \mathrm{FA}$ and a reduction in stearic (C18:0) FA content (Figure 2).

Regarding oleic FA (C18:1(n-9)), the main dietary FA, its content in BF was decreased in animals with the Iberian allele for the TAS regions on SSC8. It must be noted that the opposite effect was observed in the major SSC4 and SSC6 TAS regions for oleic (C18:1(n-9)) IMF content [17].

Effect of the SETD7:C.1034T > G and SETD7:C.700G > T SNPs and MAML3 microsatellites on gene expression

The expression profiles of the pig MAML3 and SETD7 genes were studied in liver and BF tissues of $56 \mathrm{BC} 1 \_\mathrm{LD}$ females by RT-qPCR. The analysis of gene expression in the $F_{2}$ generation was not possible because tissues for RNA isolation were not available. Differences in the expression of MAML3 among animals were observed, with
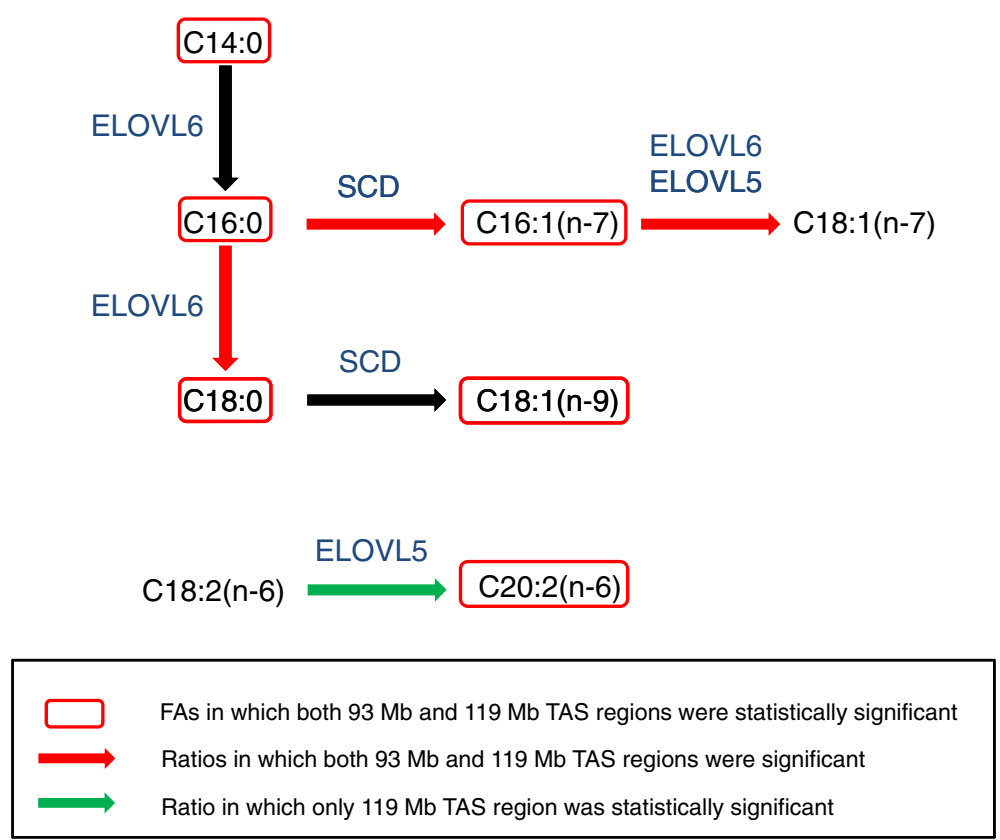

Figure 2 Schematic representation of the elongation pathway of 16 and 18 carbon FAs. Statistically significant FA (red square) and ratios of elongation and desaturation (colored arrows) are shown for BF FA composition in the $F_{2}$ generation. 
coefficients of variation (CV) of $35 \%$ and $42 \%$ in liver and $\mathrm{BF}$, respectively. The SETD7 gene expression was less variable, with CV values of $18 \%$ and $33 \%$ in liver and BF tissue, respectively. However, no significant differences in expression of SETD7 were detected among animals classified according to the SETD7 genotypes (either SETD7:c. $-1034 T>$ G or SETD7:c.700G > T) in either tissue. Similarly, no differences in expression of $M A M L 3$ were observed among animals classified according to the MAML3_MS1 and MS2 microsatellites. In addition, no significant correlation was found between expression levels of MAML3 or SETD7 in the liver and adipose, which suggests that different and tissue-specific mechanisms control the liver and adipose tissue expression of $M A M L 3$ and SETD7.

\section{Association study for BF FA composition with markers located in positional candidate genes}

Two microsatellites in the MAML3 gene (MAML3_MS1 and $M A M L 3 \_M S 2$ ), one SNP in the SETD7 gene (SETD7: c.700G > T), and one SNP in the ELOVL6 gene (ELOVL6: c. $-533 C>T$ ) were used to genotype 168 animals of the $F_{2}$ generation. An association analysis with these markers and the SSC8 genotypes from the 133 SNPs of our custom porcine SNP panel was performed.

For the first region (93 $\mathrm{Mb})$, polymorphisms in the SETD7 and MAML3 genes were studied. For SETD7, the SETD7:C.700G > T polymorphism did not show the most significant association (Table 4). In addition, MAML3 gene microsatellites showed no significant associations for any of the traits studied. However, the SNPs showing the strongest signals (Table 4) were located within a $2 \mathrm{Mb}$ interval of the SETD7 and MAML3 genes. These results suggest that other non-genotyped polymorphisms may cause the observed effects on FA composition in the $93-\mathrm{Mb}$ region.

For the second region (119 Mb), a polymorphism in the ELOVL6 gene was studied. The ELOVL6:C. $-533 C>T$ polymorphism showed the highest association with percentage of palmitic and palmitoleic FA, ACL, and C18:0/ C16:0 and C18:1(n-7)/C16:1(n-7) ratios (Table 4). Hence, these results are consistent with those found in the IMF FA composition of the BC1_LD generation [38]. The clear association of the ELOVL6:C. $-533 C>T$ polymorphism with percentage of FA in IMF and BF indicates a pleiotropic effect of this gene in both tissues.

Analysis of the additive value of SNPs SETD7:c.700G > T and ELOVL6:C. $-533 C>T$ showed a higher contribution of ELOVL6:c. $-533 C>T$ SNP for all studied FA and indices. Furthermore, the additive value of the two SNPs [See Additional file 2: Table S5] showed an effect in the same direction. For instance, the Iberian alleles of both QTL increased palmitic and palmitoleic FA content and reduced the elongation ratios. These results are in accordance with the reported Iberian-Landrace breed differences in BF FA composition [39].

Table 4 Significant SNPs affecting BF FA composition (FDR $=0.05$ ) in $168 F_{2}$ animals

\begin{tabular}{llllll}
\hline Trait & Chromosomal region (Mb) & SNP & LR & P-value & $\boldsymbol{a}$ (SE) \\
\hline C16:0 & 93.29 & MARC0024098 & 14.3307 & $1.53 \mathrm{E}-04$ & $0.645(0.828)$ \\
& 120.01 & ELOVL6:C.533C > T & 16.9446 & $3.85 \mathrm{E}-05$ & $0.652(0.818)$ \\
C16:1(n-7) & 93.62 & MARC0005229 & 23.5897 & $1.19 \mathrm{E}-06$ & $0.181(0.049)$ \\
& 120.01 & ELOVL6:C.533C > T & 33.1038 & $8.74 \mathrm{E}-09$ & $0.221(0.045)$ \\
C18:1(n-9) & 93.29 & MARC0024098 & 23.7323 & $1.11 \mathrm{E}-06$ & $-0.838(0.810)$ \\
& 117.44 & ASGA0039595 & 24.0369 & $9.45 \mathrm{E}-07$ & $-0.827(0.809)$ \\
C18:1(n-7) & 142.23 & ALGA0106925 & 13.3222 & $2.62 \mathrm{E}-04$ & $0.174(0.049)$ \\
ACL & 93.29 & MARC0024098 & 19.4268 & $1.05 \mathrm{E}-05$ & $-0.021(0.001)$ \\
& 120.01 & ELOVL6:C.533C > T & 24.7173 & $6.64 \mathrm{E}-07$ & $-0.022(0.001)$ \\
MUFA & 117.44 & ASGA0039595 & 13.8134 & $2.02 \mathrm{E}-04$ & $-0.724(1.108)$ \\
C16:1(n-7)/C16:0 & 93.62 & MARC0005229 & 16.2984 & $5.41 \mathrm{E}-05$ & $0.007(0.000)$ \\
& 127.78 & MARC0087394 & 20.5866 & $5.70 \mathrm{E}-06$ & $0.007(0.000)$ \\
C18:0/C16:0 & 93.29 & MARC0024098 & 17.2826 & $3.22 \mathrm{E}-05$ & $-0.027(0.001)$ \\
& 120.01 & ELOVL6:C.533C > T & 28.3700 & $1.00 \mathrm{E}-07$ & $-0.032(0.001)$ \\
C18:1(n-7)/C16:1(n-7) & 93.77 & MARC0020530 & 26.6172 & $2.48 \mathrm{E}-07$ & $-0.092(0.009)$ \\
& 120.01 & ELOVL6:C.533C > T & 36.7487 & $1.34 \mathrm{E}-09$ & $-0.101(0.008)$ \\
C20:2(n-6)/C18:2(n-6) & 91.93 & ALGA0048544 & 17.4256 & $2.99 \mathrm{E}-05$ & $0.009(0.000)$ \\
& 93.62 & MARC0005229 & 15.8393 & $6.90 \mathrm{E}-05$ & $-0.004(0.000)$ \\
\hline
\end{tabular}

$\mathrm{LR}=$ Likehood ratio test values; $a(\mathrm{SE})=$ additive effect (standard error). 


\section{Conclusions}

In summary, two TAS regions at $93 \mathrm{Mb}$ and $119 \mathrm{Mb}$ on SSC8 affect BF FA composition. Both regions showed a strong effect on palmitoleic acid content and C18:0/ C16:0 and C18:1(n-7)/C16:1(n-7) elongation ratios. The $M A M L 3$ and SETD7 genes were analyzed as positional candidate genes of the 93-Mb TAS region. Two novel microsatellites were identified in the MAML3 gene, and nine SNPs in the SETD7 gene. However, the association analysis did not reveal any significant association between the MAML3 microsatellite genotypes and the traits studied, and the SETD7:c.700G > T SNP did have not the strongest signal in the $93 \mathrm{Mb}$ region. Although the expression of MAML3 and SETD7 genes in liver and adipose tissue varied among animals, it was not associated with any of the genotyped polymorphisms in these genes. These results suggest that the polymorphisms studied in MAML3 and SETD7 are not the causal variants of the 93-Mb QTL. Conversely, for the 119-Mb region, the ELOVL6:c.-533C > T SNP was strongly associated with percentage of palmitic and palmitoleic FA, ACL, and C18:0/C16:0 and C18:1(n-7)/C16:1(n-7) elongation ratios. These results suggest pleiotropic effects of ELOVL6:c.$533 C>T$ on BF and IMF FA composition.

\section{Additional files}

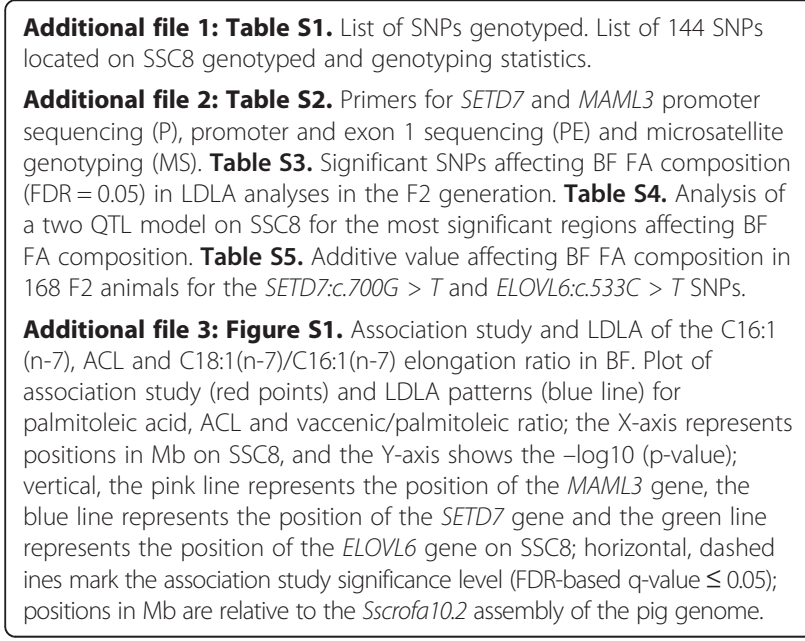

Competing interests

The authors declare that they have no competing interests.

\section{Authors' contributions}

$J M F, M B$ and $Y R C$ conceived and designed the experiment. JMF was the principal investigator of the project. NI, MM and JMF collected samples. APO, $J C, M B$ and MR performed the DNA and RNA isolation. MR, AC, JC and MB identified the polymorphisms and performed the genotyping. MR, YRC and $J C$ performed the association analysis. MR, AC, APO and MB performed the gene-expression analysis. MR and JMF wrote the manuscript. All authors read and approved the final manuscript.

\section{Acknowledgments}

This work was funded by MICINN AGL2008-04818-C03/GAN and MINECO AGL2011-29821-C02 and the Innovation Programme Consolider-Ingenio 2010 (CSD2007-00036). M. Revilla is a Master's student of Animal Breeding and Biotechnology of Reproduction (Polytechnical University of Valencia and Autonomous University of Barcelona). Y. Ramayo-Caldas was funded by a FPU grant (AP2008-01450), J. Corominas by a FPI scholarship from the Ministry of Education (BES-2009-018223) and A. Puig-Oliveras by a PIF scholarship (458-01-1/2011). This manuscript has been proofread by Chuck Simons, a native English speaking university instructor in English.

\section{Author details}

${ }^{1}$ Centre de Recerca en Agrigenòmica (CRAG), Consorci CSIC-IRTA-UAB-UB, Campus UAB, Bellaterra 08193, Spain. ²Departament de Ciència Animal i dels Aliments, Facultat de Veterinària, Universitat Autònoma de Barcelona, Bellaterra 08193, Spain. ${ }^{3}$ Genètica i Millora Animal, IRTA, Av Rovira Roure 191, Lleida 25198, Spain. ${ }^{4}$ Departamento Mejora Genética Animal, SGIT-INIA, Ctra. Coruña Km 7.5, Madrid 28040, Spain.

Received: 17 October 2013 Accepted: 10 March 2014

Published: 23 April 2014

\section{References}

1. Rothschild MF, Ruvinsky A: The Genetics of the Pig. 2nd edition. Wallingford: CABl; 2011.

2. Park GB, Moon SS, Ko YD, Ha JK, Lee JG, Chang HH, Joo ST: Influence of slaughter weight and sex on yield and quality grades of Hanwoo (Korean native cattle) carcasses. J Anim Sci 2002, 80:129-136.

3. Ventanas S, Tejeda JF, Estévez M: Chemical composition and oxidative status of tissues from Iberian pigs as affected by diets: extensive feeding v.oleic acid- and tocopherol-enriched mixed diets. Animal 2008, 2:621-630.

4. Clarke R, Frost C, Collins R, Appleby P, Peto R: Dietary lipids and blood cholesterol: quantitative meta-analysis of metabolic ward studies. BMJ 1997, 314:112-117.

5. Mensink RP, Katan MB: Effect of dietary fatty acids on serum lipids and lipoproteins. A meta-analysis of 27 trials. Arterioscler Thromb 1992, 12:911-919.

6. Wolfram G: Dietary fatty acids and coronary heart disease. Eur J Med Res 2003, 8:321-324.

7. Hunter JE, Zhang J, Kris-Etherton PM: Cardiovascular disease risk of dietary stearic acid compared with trans, other saturated, and unsaturated fatty acids: a systematic review. Am J Clin Nutr 2010, 91:46-63.

8. Astrup A, Dyerber J, Elwood P, Hermansen K, Hu FB, Jakobsen MU, Kok FJ, Krauss RM, Lecerf JM, LeGrand P, Nestel P, Risérus U, Sanders T, Sinclair A, Stender $S$, Tholstrup T, Willet WC: The role of reducing intakes of saturated fat in the prevention of cardiovascular disease: where does the evidence stand in 2010? Am J Clin Nutr 2011, 93:684-688.

9. Hu FB, Stampfer MJ, Manson JE, Ascherio A, Colditz GA, Speizer FE, Hennekens $\mathrm{CH}$, Willett WC: Dietary saturated fats and their food sources in relation to the risk of coronary heart disease in women. Am J Clin Nutr 1999, 70:1001-1008.

10. Harris WS, Poston WC, Haddock CK: Tissue n-3 and n-6 fatty acids and risk for coronary heart disease events. Atherosclerosis 2007, 193:1-10.

11. López-Huertas E: Health effects of oleic acid and long chain omega-3 fatty acids (EPA and DHA) enriched milks. A review of intervention studies. Pharmacol Res 2010, 61:200-207.

12. Ros E: Dietary cis-monounsaturated fatty acids and metabolic control in type 2 diabetes. Am J Clin Nutr 2003, 78:617S-625S.

13. Sanchez MP, lannuccelli N, Basso B, Bidanel JP, Billon Y, Gandemer G, Gilbert H, Larzul C, Legault C, Riquet J, Milan D, Le Roy P: Identification of QTL with effects on intramuscular fat content and fatty acid composition in a Duroc x Large White cross. BMC Genet 2007, 8:55.

14. Guo T, Ren J, Yang K, Ma J, Zhang Z, Huang L: Quantitative trait loci for fatty acid composition in longissimus dorsi and abdominal fat: results from a White Duroc x Erhualian intercross F2 population. Anim Genet 2009, 40:185-191.

15. Uemoto $Y$, Soma $Y$, Sato S, Ishida M, Shibata T, Kadowaki H, Kobayashi E, Suzuki K: Genome-wide mapping for fatty acid composition and melting point of fat in a purebred Duroc pig population. Anim Genet 2012, 43:27-34. 
16. Clop A, Ovilo C, Pérez-Enciso M, Cercos A, Tomas A, Fernandez A, Coll A, Folch JM, Barragan C, Diaz I, Oliver MA, Varona L, Silio L, Sanchez A, Noguera JL: Detection of QTL affecting fatty acid composition in the pig. Mamm Genome 2003, 14:650-656.

17. Ramayo-Caldas Y, Mercadé A, Castelló A, Yang B, Rodríguez C, Alves E, Díaz I, Ibáñez-Escriche N, Noguera JL, Pérez-Enciso M, Fernández Al, Folch JM: Genome-wide association study for intramuscular fatty acid composition in an Iberian x Landrace Cross. J Anim Sci 2012 , 90:2883-2893.

18. Muñoz M, Rodríguez MC, Alves E, Folch JM, Ibañez-Escriche N, Silió L, Fernández Al: Genome-wide analysis of porcine backfat and intramuscular fat fatty acid composition using high-density genotyping and expression data. BMC Genomics 2013, 14:845.

19. Pérez-Enciso M, Clop A, Noguera JL, Ovilo C, Coll A, Folch JM, Babot D, Estany J, Oliver MA, Díaz I, Sánchez A: A QTL on pig chromosome 4 affects fatty acid metabolism: evidence from an Iberian by Landrace intercross. J Anim Sci 2000, 78:2525-2531.

20. Ramos AM, Crooijmans RP, Affara NA, Amaral AJ, Archibald AL, Beever JE, Bendixen C, Churcher C, Clark R, Dehais P, Hansen MS, Hedegaard J, Hu ZL, Kerstens HH, Law AS, Megens HJ, Milan D, Nonneman DJ, Rohrer GA, Rothschild MF, Smith TP, Schnabel RD, Van Tassell CP, Taylor JF, Wiedmann RT, Schook LB, Groenen MA: Design of a high density SNP genotyping assay in the pig using SNPs identified and characterized by next generation sequencing technology. PLOS ONE 2009, 4:e6524.

21. Estellé J, Mercadé A, Pérez-Enciso M, Pena RN, Silió L, Sánchez A, Folch JM: Evaluation of $F A B P 2$ as candidate gene for a fatty acid composition QTL in porcine chromosome 8. J Anim Breed Genet 2009, 126:52-58.

22. Estellé J, Fernández Al, Pérez-Enciso M, Fernández A, Rodríguez C, Sánchez A, Noguera JL, Folch JM: A non-synonymous mutation in a conserved site of the MTTP gene is strongly associated with protein activity and fatty acid profile in pigs. Anim Genet 2009, 40:813-820.

23. Purcell S, Neale B, Todd-Brown K, Thomas L, Ferreira MA, Bender D, Maller J, Sklar P, de Bakker PI, Daly MJ, Sham PC: PLINK: a tool set for whole-genome association and population-based linkage analyses. Am J Hum Genet 2007, 81:559-575.

24. Pérez-Enciso M, Misztal I: Qxpak.5: Old mixed model solutions for new genomics problems. BMC Bioinformatics 2011, 12:202.

25. Storey JD, Tibshirani R: Statistical significance for genomewide studies. Proc Natl Acad Sci U S A 2003, 100:9440-9445.

26. Ihaka R, Gentleman R: R: A language for data analysis and graphics. J Comput Graph Stat 1996, 5:299-314.

27. Druet T, Georges M: A hidden Markov model combining linkage and linkage disequilibrium information for haplotype reconstruction and quantitative trait locus fine mapping. Genetics 2010, 184:789-798.

28. Rozen S, Skaletsky H: Primer3 on the WWW for general users and for biologist programmers. Methods Mol Biol 2000, 132:365-386.

29. Werle E, Schneider C, Renner M, Völker M, Fiehn W: Convenient single-step, one tube purification of PCR products for direct sequencing. Nucleic Acids Res 1994, 22:4354-4355.

30. Ballester M, Cordón R, Foch JM: DAG expression: high-throughput gene expression analysis of real-time PCR data using standard curves for relative quantification. PLOS ONE 2013, 8:e80385.

31. Vandesompele J, De Preter K, Pattyn F, Poppe B, Van Roy N, De Paepe A, Speleman F: Accurate normalization of real-time quantitative RT-PCR data by geometric averaging of multiple internal control genes. Genome Biol 2002, 3:RESEARCH0034

32. Karim L, Takeda H, Lin L, Druet T, Arias JA, Baurain D, Cambisano N, Davis SR, Farnir F, Grisart B, Harris BL, Keehan MD, Littlejohn MD, Spelman RJ, Georges M, Coppieters W: Variants modulating the expression of a chromosome domain encompassing PLAG1 influence bovine stature. Nat Genet 2011, 43:405-413

33. Oyama T, Harigaya K, Sasaki N, Okamura Y, Kokubo H, Saga Y, Hozumi K, Suganami A, Tamura Y, Nagase T, Koga H, Nishimura M, Sakamoto R, Sato M, Yoshida N, Kitagawa M: Mastermind-like 1 (MamL1) and mastermind-like 3 (MamL3) are essential for Notch signaling in vivo. Development 2011, 138:5235-5246.

34. Pajvani UB, Qiang L, Kangsamaksin T, Kitajewski J, Ginsberg HN, Accili D: Inhibition of Notch uncouples Akt activation from hepatic lipid accumulation by decreasing mTorc1 stability. Nat Med 2013, 19:1054-1060.
35. Syreeni A, El-Osta A, Forsblom C, Sandholm N, Parkkonen M, Tarnow L, Parving HH, McKnight AJ, Maxwell AP, Cooper ME, Groop PH, Finn Diane Study Group: Genetic examination of SETD7 and SUV39H1/H2 methyltransferases and the risk of diabetes complications in patients with Type 1 diabetes. Diabetes 2011, 60:3073-3080.

36. Chakrabarti SK, Francis J, Ziesmann SM, Garmey JC, Mirmira RG: Covalent histone modifications underlie the developmental regulation of insulin gene transcription in pancreatic beta cells. J Biol Chem 2003, 278:23617-23623.

37. Ramayo-Caldas Y, Mach N, Esteve-Codina A, Corominas J, Castello A, Ballester M, Estelle J, Ibañez-Escriche N, Fernandez Al, Perez-Enciso M, Folch JM: Liver transcriptome profile in pigs with extreme phenotypes of intramuscular fatty acid composition. BMC Genomics 2012, 13:547.

38. Corominas J, Ramayo-Caldas Y, Puig-Oliveras A, Pérez-Montarelo D, Noguera JL, Folch JM, Ballester M: Polymorphism in the ELOVL6 gene is associated with a major QTL effect on fatty acid composition in pigs. PLOS ONE 2013, 8:e53687.

39. Serra X, Gil F, Pérez-Enciso M, Oliver MA, Vázquez J, Gispert M, Díaz I, Moreno F, Latorre R, Noguera JL: A comparison of carcass, meat quality and histochemical characteristics of Iberian (Guadyerbas line) and Landrace pigs. Livest Prod Sci 1998, 56:215-223.

\section{doi:10.1186/1297-9686-46-28}

Cite this article as: Revilla et al:: New insight into the SSC8 genetic determination of fatty acid composition in pigs. Genetics Selection Evolution 2014 46:28.

\section{Submit your next manuscript to BioMed Central and take full advantage of:}

- Convenient online submission

- Thorough peer review

- No space constraints or color figure charges

- Immediate publication on acceptance

- Inclusion in PubMed, CAS, Scopus and Google Scholar

- Research which is freely available for redistribution 